\title{
EXPERIMENTAL LESION OF THE CORPORA QUADRIGEMINA IN MONKEYS.
}

\author{
BY DAVID FERKIER, M.D., F.R.S. \\ AND
}

WILLIAM ALDREN TURNER, M.D.

From the Neuropathological Laboratory, King's College, London.

IN the course of our investigations upon the symptoms and degenerations following experimental lesion of the several portions of the mid and hind brain, elsewhere described (1), partial lesions of the quadrigeminal bodies and of the subjacent tegmentum were produced. It was therefore considered advisable, both from the importance of the anatomical connection of these bodies, as well as from the variable and uncertain results obtained by previous investigators, to make a further series of experiments with a view to their complete, and as far as possible limited, ablation. In the present communication the symptoms of our experimental lesions will alone be described, leaving for a future communication an account of the degenerations so induced.

The functions of the corpora quadrigemina have been the subject of many researches, but considerable uncertainty still exists as to their true physiological significance. There seems to be an inverse relation between the development and functional importance of the quadrigeminal bodies-optic lobes of fishes, amphibia and birds-and the cerebral hemispheres; and in the second place the anterior and posterior pairs have respectively different anatomical connections with the other parts of the central nervous system. Hence the experimental data may be expected to vary according as the observations are made upon lower vertebrates such as fishes, 
frogs and birds, or on the higher mammals such as monkeys, and as to whether the lesions affect the anterior or posterior pair or both.

From a review of the earlier literature upon the functions of the optic lobes or corpora quadrigemina, as observed by the method of destructive lesions, the results may be summarised under the following heads.

(1) Vision,-Various observers, among whom may be mentioned Longet (2), Flourens (3), Schiff, McKendrick (5), Ferrier (6) and Bechterew (7), found a constant relation existing between the anterior lobes and the sense of sight. Destruction of the optic lobes gave rise to visual defect, but the extent of the loss of vision was dependant upon the complete or partial decussation of the optic tracts. In those animals whose vision was monocular with complete decussation at the chiasma, removal of an optic lobe occasioned blindness in the opposite eye; while in those with binocular vision, there resulted hemianopsia to the right or left according as the left or right anterior bodies were destroyed. The experimental observations of Bechterew upon dogs are the most complete in this connection. For example, destruction of one anterior body gave rise to homonymous hemianopsia to the opposite side, and a like result followed unilateral destruction of both bodies. The pupillary reaction was only affected if the lesion extended deep into the Sylvian gray matter. A complete lesion of both anterior bodies produced complete blindness. This last observation is in harmony with one by Ferrier, who found complete blindness after destruction of both anterior quadrigeminal bodies in a monkey.

The more recent experimental observations of Fano (7A), upon testudo, and of Stefani (4) upon birds, showed that althougb there was some impairment of vision, as a result of destruction of the optic lobes, it was clear that vision was not entively abolished.

The results of these experiments therefore are in favour of the view that destruction of the anterior pair, whether in the lower vertebrata, such as fishes, frogs or birds, or amongst the nammalia, such as dogs or monkeys, is followed 
by impairment or abolition of the sense of sight. The observations of Nothnagel (8), on the other hand, upon the effects of disease of this region in man failed to prove any interference with vision which could be ascribed to lesion of the quadrigeminal bodies as such. In a case of bullet wound of these bodies upon the right side, recorded by Eisenlohr (9), there was no affection of vision immediately after the receipt of the injury. Although the relation of the optic lobes to vision may be clear in the lower forms of vertebrate life, it is by no means so certain between the corpora quadrigemina and the sense of sight in the higher mammalia. The facts which we bring forward in this paper make it clear that ablation of the quadrigeminal bodies as such in monkeys is not followed by any impairment of vision.

(2) Reflex action of the pupils. - Some observersFlourens, Longet, and others-found that the destruction of the quadrigeminal bodies caused, in addition to loss of vision, dilatation of the pupil and loss of the pupillary light reflex-an observation which indicated a centre co-ordinating retinal impressions and irido-motor action. On the other hand, Knoll (10), experimenting on rabbits, and Bechterew on dogs, did not confirm the pupillary immobility after destruction of these bodies. It was only observed by the former when the optic tract was itself injured, and by the latter if the lesion was sufficiently extensive so as to involve the gray matter around the Sylvian aqueduct.

(3) Associated movement of the eyeballs.-The phenomena observed upon stimulating the quadrigeminal bodies -Ferrier, Adamuk (11), Bechterew-show that, in addition to tonic spasm of the body and limbs, ocular movements of a definite character have been noticed, such as dilatation of the pupils, opening of the eyes and elevation of the eyebrows, and conjugate deviation of the eyes to one or other side. These phenomena have been ascribed by some to diffusion current, as some of the results may also be obtained by irritation of the subjacent tegmentum after the quadrigeminal bodies have been removed. On the other hand, it has been claimed that the results of stimulation are due to irritation of the quadrigeminal bodies, as such; for the 
effects of irritating the anterior pair differ essentially from those consequent on irritation of the posterior pair.

This view would seem to receive confirmation from the recent stimulation experiments of Prus (18). From his experiments, which were made upon dogs without narcosis, this observer concluded that in the anterior and posterior bodies respectively are centres for influencing visual and auditory impressions, that in the anterior pair there is a centre for tonic, and in the posterior pair a centre for clonic convulsions, and that through these bodies there pass reflex paths for respiration and vasomotor action.

(4) Maintenance of equilibrium. - Serres in 1827, first pointed out that destruction of the corpora quadrigemina in various animals gave rise to marked instability and disorders of equilibration. These observations were confirmed by numerous investigators-Cayrade (13), Goltz (14), Kohts (1.5), McKendrick, and Ferrier. Thus fishes, although able to swim, could not maintain the normal attitude : frogs rolled over and over and were unable to balance themselves; pigeons, when thrown into the air, oscillated and fell down, and rabbits showed marked instability during locomotion. On the other hand Bechterew, experimenting chiefly on dogs, failed to find any disturbance of gait or locomotion after destruction of the quadrigeminal region. When these defects were present, the subjacent structures had been injured, and more especially the superior cerebellar peduncle.

A reeling gait has been described as characteristic of disease, especially tumour, of the quadrigeminal region in man. In appearance it resembles that seen in cerebellar disease rather than that of locomotor ataxy. If the disease is progressive, locomotion and the maintenance of equilibrium eventually become impossible. These symptoms have been attributed to implication of adjacent structures, rather than to interference with the functions of the quadrigeminal bodies as such. In the light of our experiments here recorded, where no ataxy or disturbance of equilibriun was observed-provided the lesion did not extend beyond the limits of the ganglionic structures-this would seem to be the true explanation. 
(5) Hearing.-Destruction of the posterior pair was found by Bechterew, experimenting on white rats and dogs, to be followed by defect or abolition of the sense of hearing, according as the lesion was partial or complete. Only when the lesion was quite superficial did hearing seem to be unimpaired. The close association which is known to exist anatomically between the posterior pair and the trapezoid body, by means of the lateral fillet, would appear to point to an important relation between these structures and the sense of hearing. But even under the most favourable conditions it is difficult to estimate with any certainty the degree of deafness in animals; and in disease of this region in man, in which the state of hearing was specially investigated, the results are very uncertain. In the only one of our experiments (No. 2), in which the facts seemed to warrant the existence of deafness, the lesion was so extensive that not only the quadrigeminal bodies, but also the tegmentum and the central auditory tract, were destroyed. In experimental cases, therefore, in which hearing is said to have been abolished, unless a subsequent microscopic examination has been made, the direct dependance of deafness upon the quadrigeminal lesion may be open to question.

(6) The voice and emotions.-Some of the earlier investigators, more particularly Goltz, were of opinion that the quadrigeminal bodies are a centre for emotional expression, but the more careful observations of later experimenters have not corroborated this view. Bechterew states that ablation of the anterior quadrigeminal bodies does not produce any affection of the emotions, but that, if the posterior pair are destroyed, weakness of the voice may ensue, and that it may be completely lost if the lesion is bilateral and extensive. Ferrier, on the other hand, produced extensive lesions of these bodies in rabbits without causing cessation of the characteristic cries evoked by sensory stimulation.

Onodi (16) also has separated the quadrigeminal region from the higher part of the brain without interfering with the approximation of the vocal cords; while Sherrington (12) 
found vocalisation abolished after transection immediately behind the posterior bodies in monkeys.

(7) Bodily temperature.-Some experiments by Ott (17) upon puncture of the quadrigeminal bodies in rabbits showed a rise of from $1^{\circ}$ to $2^{\circ} \mathrm{F}$., which lasted for three or four hours. According to this observer, these effects were due to disturbance of a thermolytic centre in this locality. Irritation of the quadrigeminal region has also been found to increase the blood pressure, as well as to modify the respiratory rhythm.

\section{Method of Operation.}

Young monkeys-Macacus sinicus and rhosus-were exclusively employed. After deep anæsthesia was produced a considerable extent of bone was removed from the left side of the skull posteriorly and laterally, so as to expose the occipital lobe and the greater part of the angular gyrus. The dura mate: being reflected, the occipital lobe was cut off at the parieto-occipital fissure, and the tentorium-cerebelli was incised back to the lateral sinus. By means of small pieces of sponge the anterior folia of the cerebellum upon both sides were carefully and gradually displaced backwards, so as to expose the quadrigeminal bodies and the veins of Galen. With care the latter could be avoided, while the ganglia were destroyed by the galvano-cautery.

In one of the earlier experiments the occipital lobe was not removed, but it was found impossible to obtain a clear view of the ganglia without removal of the occipital lobe; so that this practice was resorted to in all the later experiments, for in order to limit the lesions to these bodies, it is expedient that they should be fully exposed. Bleeding from the veins of Galen is the most serious accident which may happen. The shock of the operation is considerable and stoppage of respiration was observed on several occasions when the cautery was being applied; but further reference will be made to this.

\section{Experimental OBSERVATIONS.}

Experiment 1. Macacus rhœsus.-Immediately after the operation, the knee-jerks were obtained equal upon the two 
sides and of normal range. The pupils were contracted to the size of pin-points, and the eyeballs were deviated to the left side.

On recovery from the shock of the operation the following observations were made: When placed on the floor the monkey hastened off to the side of the room, the gait being perfectly steady, not the slightest tendency to fall over or stagger being detected. There was no sprawling of the limbs nor were there any tremors. On one or two occasions when startled by a loud noise he was seen to fall, but rapidly recovered his stability.

There was clear evidence of hemiopia towards the right side. As regards hearing, when a bunch of keys was jingled to right or to left, a reflex movement of the corresponding auricle was observed. There was no impairment of ordinary cutaneous sensation.

Four days later the pupils were seen to be of normal size. The eyes were moved naturally either to right or left. There was no ptosis, nor any defect in the movements of the eyelids. As far as the observation can be relied upon when tested in a monkey, the pupillary light reaction was present. The gait was steady, climbing was easily accomplished and the grasps were good. The knee-jerks were natural.

During the first few days after the operation the monkey showed a slightly paretic condition of the legs, but this did not interfere either with walking or with climbing. It passed off after the first week.

During the month the animal lived after the operation, with the exception of the right-sided hemiopia, no symptoms were detected. He was well and active, and moved freely about the cage. He was killed under chloroform, one month after the infliction of the lesion.

Autopsy.-The left occipital lobe had been removed. The cerebellum was intact. The lesion of the quadrigeminal. region was practically complete. The only portions remaining were the anterior border of the nates on the left side and the posterior margin-linear in extent-of the testes (fig. 1).

Microscopically.-Examination of the sections at the level voL. XXIV. 
of the lesion showed that the ganglionic masses had been entirely removed, the line of demarcation passing through part of the Sylvian gray mater in the proximal parts and immediately dorsal to the posterior longitudiual bundles in the distal sections. The superior cerebellar peduncles, fillets, and internal geniculate bodies were intact.

Experiment 2. Macacus rhossus.--Three-quarters of an hour after the operation the knee-jerks were obtained, but that on the left side was more active than the right. Both pupils were small, but cot contrated to the size of pinpoints; there was no deviation of the globes. 'The monkey was lively and able to move its limbs freely. He was able to raise himself without falling over or swaying. On the following day he was able to progress well, without any unsteadiness or tendency to fall. The usual tests showed that there was hemiopia towards the right side, and also a blunting of both tactile and painful sensation, and defect of localisation on the left arm and leg, and the left ear was also anæsthetic, as well as the left side of the face. There was no loss of motor power, as he was able to climb the lattice of the cage freely and to hold on tightly. There was no tremor on volitional effort.

It was difficult to be sure of the facts regarding hearing. No notice was taken of keys when jingled behind his back, nor was an auricular reflex obtained from either ear.

With the exception of a return to a medium size of the pupils-the left, however, remaining somewhat larger than the right-no change was detected in the symptoms during the ten days that the animal lived after the operation. At no period did he show any unsteadiness or ataxy.

Autopsy.-The superficial appearance of the lesion is shown in fig. 2. The left occipital lobe had been removed, and the cerebellum was intact. The lesion of the quadrigeminal bodies was the most complete of the series of experiments, no part of the superficial area of these structures being left.

Microscopically.-The sections showed that the lesion was very extensive, passing deeply into the tegmentum cruris on the right side. In this way there were destroyed 
the tegmentum cruris, the mesial fillet, and the central anditory tract on that side. The nucleus ruber and superior cerebellar peduncle essaped. The nucleus of the third cranial nerve was intact. The right internal geniculate body was partly destroyed, but that on the left side was untouched.

In the distal or pontine sections the extent of destruction was the same as in the previous case, the line of the lesion passing immediately dorsal to the posterior longitudinal bundles.

Experiment 3. Macacus sinicus.-Within a quarter of an hour of the performance of the operation the monkey was able to sit up without support. The knee-jerks were equally and readily obtained. The pupils were contracted, but there was no deviation of the eyeballs.

On the following day one was unable to observe any evidence of instability of movement, the monkey sat up without any support and showed no tendency to fall even when incited to hurry. He was absolutely steady both when progressing along the floor and when climbing the lattice of the cage, and even when sitting upon a perch.

There was hemiopia towards the right side shown by the usual tests, and for one or two days after the operation there appeared to be some defect of sensation down the right side. There was no note upon the state of hearing. The monkey remained perfectly well for one month, when he was killed under chloroform.

Autopsy.-The left occipital lobe had been removed. The extent of superficial destruction of the quadrigeminal bodies is shown in fig. 3 . From this it is evident that the region had been completely destroyed with the exception of a linear zone corresponding to the hind margin of the posterior bodies.

Microscopically.-In this case the sections showed that the ganglionic masses had not been entirely destroyed in the deeper parts, and that the adjacent and subjacent structures, fillets, superior peduncles and geniculate bodies were intact.

Experiment 4. Macacus rhosus.-Immediately after the operation the knee-jerks were obtained, the left being some- 
what more active than the right. There was also deviation of both eyeballs to the left, and the pupils were small and equal. Owing to a considerable amount of prostration, no observations upon the gait and other functions were made until the third day, when the following were observed.

By this time the knee-jerks were equal, the pupils of medium size, and the movements of the globes unimpaired. Instead of walking across the floor in a natural way the monkey was seen to pivot upon his buttocks, but there was. no instability or falling, unless he were urged. The movements of the left arm and leg appeared defective, but this was due to the anæsthesia and analgesia, which extended over the whole of the left side of the body and limbs.

The appearance of the animal suggested a careful testing of vision; and the result showed that the sight was abolished on both sides. He took no notice of pieces of apple placed before him, or of a lighted taper brought in front of his eyes. He only picked up food when it was placed in contact with the right hand. No definite facts were ascertained regarding hearing. There was no response by blinking or starting when a noise was made near him, nor any auricular reflex when keys were jingled before his ears.

At the end of one week he remained in the same condition. He groped about the floor in an aimless way, evidently because he did not see at all. There was still leftsided anæsthesia, but no instability or tremors.

During the second week it appeared as if there were some vision. He took no notice of objects anywhere to the right, but pieces of apple when held immediately to the left side of the nose were seized. There was no evidence of vision in the outer parts of the left visual fields. Towards the end of this week slight but not constant tremors were observed in the left arm on volitional effort, such as were seen in cases in which a lateral cerebellar lobe had been removed. There was no further evidence of hearing and the left-sided anæsthesia remained as before. The monkey remained without any material change in this condition for one month after the operation. By this time, however, there was evidence that he seemed to hear, for a reflex was obtained 
from both auricles when keys were rustled beside his ears, or when the hands were clapped in proximity to his head. The animal died six weeks after the operation.

Autopsy.-The left occipital lobe had been removed and the anterior part of the left cerebellar hemisphere was largely softened. On removing this the nature and extent of the lesion of the quadrigeminal region was apparent. This was complete, no trace of the bodies remaining. On the right side, however, the lesion extended forwards and outwards so as to invade the posterior part of the optic thalamus and the interial capsule.

Microscopically.-The sections proved the extension forwards of the lesion into the right pulvinar thalami and adjacent internal capsule. The right tegmentum cruris also was invaded, so as to involve the mesial fillet and the central auditory tract.

The explanation of the clinical phenomena in this case was therefore apparent, the blindness being due to the removal of the left occipital lobe combined with destruction of the optic radiations in the retrolenticular part of the right internal capsule and pulvinar thalami.

Experiment 5. Macacus rhosus. - Immediately after the operation both pupils were found to be contracted to the size of pin-points, but after the lapse of about an hour became of normal size. There was deviation of both globes to the left side, the right eye having an inclination downwards, the left eye upwards. Occasional nystagmoid jerkings of the globes were also seen. All the ocular phenomena had passed away by the morning of the next day.

The knee-jerks were readily obtained and equal. On the next morning the monkey was again observed, when it was found that he could move his limbs freely, that there was no unsteadiness of gait nor any tendency to fall or to sprawling of the limbs. He sat quite steadily without swaying. Nothing definite, however, was made out as regards vision, hearing or common sensation.

Autopsy.-Fig. 4 shows the superficial extent of the lesion. This was incomplete inasmuch as the anterior and 
posterior margins of both pairs were intact. On examining the sections through the intermediate or destroyed zone, it was seen that the deeper portions had not been completely destroyed. The Sylvian aqueduct had not been opened. The fillets, central auditory tract and tegmentum were intact.

Experiment 6. Macacus rhcesus.-The monkey recovered rapidly, and was found to move his limbs freely; when raised he fell backwards to the left side, and was quite unable to sit up without support. The left pupil was more contracted than the right, and there was a very slight conjugate deviation of both eyes to the left. The knee-jerks were not obtained.

On the following day the animal was well and active. When placed on the floor he lay on his belly, but when urged to move on rising he invariably fell to the left side, but there was no rotation. On volitional movement, viz., when food was placed between the lips, there was tremor of the head, and if the left hand was brought up to the mouth, tremors were also observed in it. There was no limb palsy, as he held on firmly both with hands and feet. There was hemianopia to the right side, but no interference with cutaneous sensation.

At the end of a week the symptoms remained the same, the most obvious being a coarse tremor of the bead and body on movement, such as taking food, having the characters seen in disseminated sclerosis in man. The movements of the right arm appeared to be steady, but when the left was brought into use the characteristic "intention tremor" was noted. The gait was unsteady. The kneejerks remained in abeyance. Ten days after the operation the monkey presented the following appearances: The left arm was maintained in a flexed and adducted position, and a rhythmic tremor observed in it, even when the animal was apparently at rest. These movements occasionally ceased, but on attempting to lay hold of food they became wild and incoordinated. The gait was unsteady, with a tendency to fall to either side. The appearances presented by this monkey were in all respects comparable to those previously 
seen in cases of cerebellar extirpation and lesion of the superior cerebellar peduncle.

The linee-jerks remained absont throughout. Hearing was not tested. The monkey died upon the twelfth day after the operation.

Alutopsy.-In this case the lift occipital lobe had not been removed. 'The lesion of the quadrigeminal region was incomplete. The left posterior body was completely destroyed, while that on the right side was only partially so. Both anterior bodies were intact (fig. j). The left superior cerebellar peduncle, shortly before it entered the termentum pontis, was found to have been considerably injured. The tegmentum itself was not injured in any way. The microscopical sections comoborated the existence of a complete lesion of the left posterior body, while the stuperior cerebellar peduncle was found to be extensively injured.

Exporiment 7. Mucacus rha'sus.-In this case after the operation the pupils were found to be dilated and equal. 'Lhere was a slight deviation of both eyes to the left, but no nystignoid morements. 'The linee-jerlis were present and equal. On the following day when more fully cximined the nonkey was observed to be able to walk, but tended to fall towilrts the right side. The rilit was unsteady, and a sprawling action of the limbs was noticed. When sitting up, which lie did without support, rocking morements of the body were observed. 'There was anisthesia and mal gresia down the right side of the body and limbs, and right-sided hemianopia. I'wo dilys after the operation nell marked intention-tremors were detected in the left arm on rolitional movement, such as picking up a piece of fiuit, the right hind being used to steady the left. The swaying movements of the body persisted, but the gencral disturbances of locomotion were less. These appearances were observed until the deith of the monkey on the seventh day after the operation.

Autopsy (lig. (i).-The bodies upon the left side both anterior and posterior, and the posterior body upon the right side, were found to have been destroyed, but the right 
anterior body was intact. The lesion, however, had extended deeply into the teginentum on the left side. This was so extensive as almost to consist of a hemisection, the left superior cerebellar peduncle and mesial fillet being implicated.

In two other experiments (8 and 9) immediate phenomena only were observed, as the animals did not live sufficiently long to permit of further investigation. In both the pupils were contracted to the size of pin-points, but there is no note of any deviation of the globes.

In both cases during the performance of the experiment, while the bodies were being destroyed by the cautery, respiration ceased, but was restored after an interval by the performance of artificial respiration. One lived 40 hours, the other 12 hours after the operation.

In experiment 8 both anterior and the left posterior bodies were destroyed, the right posterior being intact. In experiment 9 all the bodies were destroyed with the exception of the right anterior.

\section{Analysis of the Phenomena following Destruction of the Quadrigeminal Bodies.}

The pupils.-In all the experiments with the exception of No. 7 the pupils were, immediately after the operation, contracted to the size of pin-points. In the exceptional case they were dilated, but reference to the record will show that the lesion was less one of the quadrigeminal region than of the tegmentum of the pons. This pin-point contraction was only a temporary phenomenon, for in two days at most after the operation the pupils had returmed to their natural size.

As regards the pupillary light re-action, in the cases in which it was tested it appeared to be present (so far as reliance may be placed on this re-action when tested in animals, where it is so difficult to eliminate the complication of convergence and accommodation).

Ocular movements. - In all the cases with the exception of Nos. 2 and 3 the globes were deviated to the left side. 
This deviation was not of more than a few hours' duration. The explanation of this was not clear. The operations were all performed from the left side and with one exception the left occipital lobe was removed. Removal of this lobe, however, and the consequent hemianopsy is not sufficient to explain the deviation; nor does an unequal though bilateral destruction of the quadrigeminal region satisfactorily account for it, for it was absent in experiments 2 and 3 where the ablation was as complete as in Nos. 1 and 4, in which no deviation was noted. It was also observed in Nos. 6 and 7 , where the lesion was incompletely bilateral.

It may be noted in this connection that a temporary deviation of the globes may likewise follow lesion of a cerebellar hemisphere or of the cerebellar peduncles, while we had previously observed it also in lesions limited to the tegmentum cruris.

As regards the ocular movements after the immediate phenomena had passed away, in no instance was ptosis or ophthalmoplegia detected. The absence of oculo-motor paralysis was accounted for by the fact that in no case was the lesion sufficiently deep or far forward to implicate the nucleus of the third cranial nerve.

Knee-jerks. - With the exception of No. 6 the kneejerks were obtained throughout and equally on the two sides. In the exceptional instance they were not obtained at all, nor was any complication noted to account for their absence, with the possible exception that the monkey was in a condition of poor nutrition.

Station and locomotion. - It is in this connection that the most characteristic symptoms of gross disease of the quadrigeminal region in man are observed. We may therefore at the outset state that in the five uncomplicated cases of quadrigeminal ablation, in which the lesion was complete and bilateral, no disturbance of stability or locomotion was observed from the time of the operation until death. Monkeys with this lesion were able to move freely, climb the lattice work of the cage, and even to perch upon the ropes and bars.

In the two experiments (Nos. 6 and 7 in which con- 
siderable instability was detected with sprawling of the limbs during progression, falling about and tremors of the limbs and body, adjacent structures were injured. In No. 6 the superior peduncle was implicated, and in No. 7 the lesion extended deeply into the tegmentum and involved the superior cerebellar peduncle and mesial fillet.

As might be inferred from the retention of equilibrium and the absence of instability no loss of motor power was detected. In every instance the monkey grasped firmly both with hands and feet. In experiment 1 what appeared to be a paresis of the legs was observed, but it was quite transitory and did not interfere with locomotion.

Sensation.-The observations upon the cutaneous sensation were variable. But it is evident that a lesion limited to the quadrigeminal bodies, as such, was not accompanied by any impaiment of cutaneous sensibility, as in the three experiments, 1,5 and 6 , where the lesion was accurately defined. In No. 2 anæsthesia, analgesia and defect in the sense of localisation was observed on the left side. In this case these phenomena were due to an extensive implication of the tegmentum cruris on the right side. In experiment 4 there was complete left-sided anæsthesia and analgesia occasioned by the extension forwards of the lesion into the right internal capsule and optic thalamus; and in experiment 7 there was anæsthesia on the right side of the body from a lesion of the left tegmentum pontis.

These observations are in agreement with what has been noted in cases of disease of this region in man, namely, that if sensory disturbances exist they are referable to implication of adjacent structures, such as the internal capsule or tegmentum.

Vision.-Early in the investigation it was found necessary to remove an occipital lobe in order to sufficiently expose the quadrigeminal bodies. That the right-sided hemianopsy which was present in six out of the seven experiments arose from ablation of the left occipital lobe is obvious from the fact that no additional visual defect was produced by destruction, partial or complete, of the quadrigeminal region on both sides. In experiment 4, 
where the monkey was rendered temporarily blind, reference to the record will show the co-existence of a left-sided hemianæestbesia, which with the left hemianopsia was due to an accidental lesion of the posterior part of the right internal capsule.

There is here therefore cogent evidence in support of the view that destruction of these bodies has no direct influence upon vision. If this were not so, the complete destruction which was effected in experiments 1, 2 and 3 ought to have caused total blindness.

Hearing.-Even under the wost favourable conditions for testing, it is difficult to be certain as to the presence of deafness in an animal. Reliance in testing was placed upon the monliey's attention being arrested by sounds, such as the jingling of keys, at times when it was otherwise occupied, and by the presence or absence of the auricular reflex. Even in experiment 4, where the animal was blind, and the possibility of fallacy less likely, the state of hearing was uncertain.

In only one case to all the usual tests did the animal appear to be deaf, and in this instance subsequent detailed examination revealed an extensive and deep lesion of the tegmentum with implication of the central auditory tract. In experiment 1, where the lesion was accurately limited to the ganglia, there was no obvious evidence of deafness. From this it would seem that lesion of the quadrigeminal bodies as such is not productive of impairment of hearing, a fact which the anatomical connections of the posterior pair corroborates.

The voice.-There were $n o$ observations which led us to the belief that the voice or the emotions were affected by this lesion.

Respiration.-In two expcriments, Nos. 8 and 9, in which detailed observations were not made owing to the short duration of life after the operation, respiration suddenly stopped at the time when the ganglia were being destroyed, even though the animals were well under the influence of the anwsthetic. On the employment of artificial methods the respiritory movements returned. 


\section{Conclusions.}

The results of these experiments show quite clearly that destructive lesions limited to the ganglionic masses of the quadrigeminal region are not productive of any obvious permanent phenomena; for after the disappearance of some transitory symptoms, such as contraction of the pupils and deviation of the eyeballs, no residual effects are observed. Should such definite phenomena as instability of gait, tremors on volitional effort, anæthesiæ and defects of vision be obtained they are to be explained as the results of injury to adjacent and subjacent structures, such as the cerebellum, the superior cerebellar peduncle, the tegmentum cruris, the optic thalamus, the internal capsule, the optic radiations and the occipital lobe.

A short statement of the anatomical connections of these bodies so far as at present known, may help to explain the very subsidiary nature of their functions. Two chief sets of fibres pass to the superficial layers of the anterior pair, one from the occipital lobe reaching their destination by way of the optic radiations and the pulvinar thalami, while the other is derived from the optic tract. A few fibres from the mesial fillet appear also to enter the anterior pair. What the outgoing fibres of the anterior bodies are is not so clear. That fibres stream out and decussate in the "fountain decussation" seems certain, but the fact that there is no degeneration in the spinal cord after removal of the quadri. geminal bodies shows that descending efferent fibres do not pass directly into this structure.

The afferent fibres of the posterior pair are mainly derived from the accessory auditory ganglion of the opposite side crossing by way of the corpus trapezoides and entering the posterior pair through the lateral fillet. What has been described as the central auditory tract lies ventral to the posterior bodies as it passes upwards to the internal geniculate body, and has no direct connection with the posterior pair.

It is an interesting fact also that although the occipital corticifugal fibres terminate in the anterior bodies, no cor- 
responding corticifugal fibres are found in the posterior bodies after ablation of the first and second temporal gyri.

It would therefore seem, when the anatomical connections are studied in association with the almost negative results of physiological extirpation, that the quadrigeminal bodies have only a very subsidiary relation to the special senses of sight and hearing.

It is difficult to understand the retention of irido-motor ind general oculo-motor action after complete ablation, if the anterior bodies are the centres for co-ordinating visual impressions with the movernents of the eyeballs. The only explanation would seen to be that the pupillary fibres of the optic nerve reach the third cranial nucleus by some oiber route than through the anterior quadrigeminal bodies, as indeed Bechterew has maintained.

We have attempted to account for the absence of deafiness in strictly limited quadrigeminal lesions, by referring to the fact that the central anditory tract lies outside these ganglia, the posterior quadrigeminal body being merely an accessory structure and end station of the fibres of the lateral fillet.

The relatively small functional value of the quadrigeminal borlies in man and the monkey, as detormined by these experiments, is in distinct contrast to their importance in the lower vertebrates, such as fishes, frogs and birds, assuming that the experinental lesions in these animals have been of a strictly limited character. 'The most likely explanation of this difference is to be sought for in the greater development and increased physiologrical value of the cerebral centres in the ascent of the vertebrate scale, and with this there is in corresponding diminution in their sire both absolutely and rolitively.

\section{RHEWRENCLSS.}

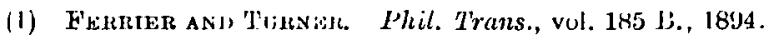
Fermier and 'Tulewir. J'hil. Trans., vol. 190 B., 1898.

(2) LunGEv. A.nat. et Phys. du sys. Nerv., 1869.

(i3) Floutens. Richerches lixperimentales, de., 1824.

(4) STwFan. lieferred by Sherrington. "Text-book of Lhysiulogy," kid. by Schifiır, 1900.

(ii) Mckindack. Truns. Moy. Soc., Edin., 187:!. 
(6) Ferrier. "Functions of the Brain," 1886.

(7) Bechtenew. Arch. f. Physiol., 1884.

(7A) Fano. Referred by Sherrington. "Text-book of Physiology," Ed. by Schïfer, 1900 .

(8) Nothnagel. Brain, 1889.

(9) Eisenlohr. Neur. Central., 1890.

(10) KNoLL. Eckhard's Beiträge, 1869, vol. iv.

(11) Adanuk. Central.f. d. med. Wissensclu, 1870.

(12) Sherrington. Proc. Roy. Soc., 1896, vol. Ix.

(13) Cayrade. Journ, de l'Anat. et Physiol., 1868.

(14) Gortz. Funct. der Nervencentren, 1869. 180.

(15) Koнтs. Virchow's Archiv., 1876, vol. lxvii.

(16) Oxodi. Berl. Klin. Wochensch., 1894, p. 48.

(17) Отт. Jonurn. of Nerv. and Ment. Dis., 1891.

(18) Prus. Wiener Klin. Wochensch., 1899. No. 45.

DESCRIPTION OF THE FIGURES.

FIG. 1.

Superficial appearance of the lesion in experiment 1. It will be noted that the whole of the superficies of the quadrigeminal region is destroyed, with the exception of a small portion of the left anterior body.

Fig. 2.

The lesion in experiment 2. In this case it extended deeply into the tegmentum.

FIG. 3. tion.

The lesion from experiment 3 , showing a complete superficial destruc-

Fig. 4.

The appearance of the lesion in experiment 4 . This lesion is incomplete in so far as the anterior and posterior margins of the bodies are intact.

Fig. 5.

The appearance of the lesion in experiment 6 . The destruction is practically limited to the posterior pair.

Fig. 6.

Represents the lesion in experiment 7. This is also incomplete in that the right anterior body is intact, the others being destroyed. 

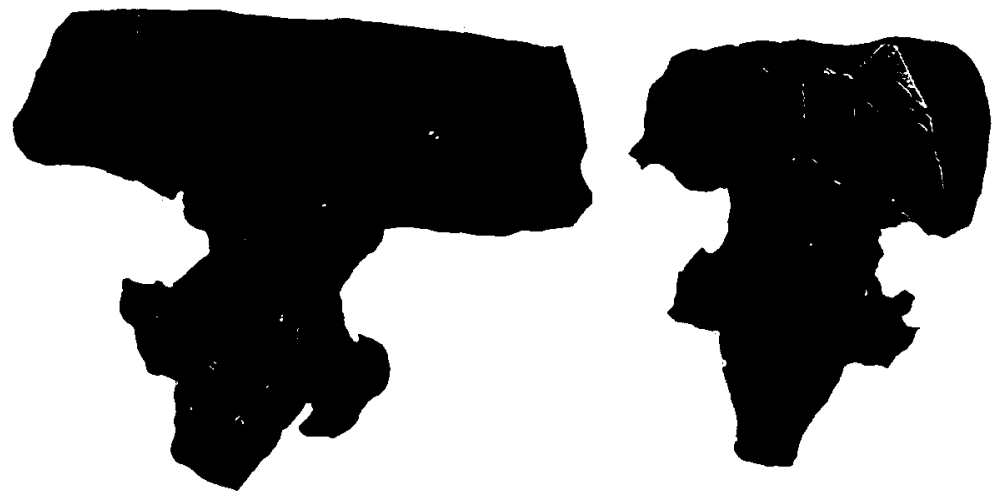

Fig. 1.

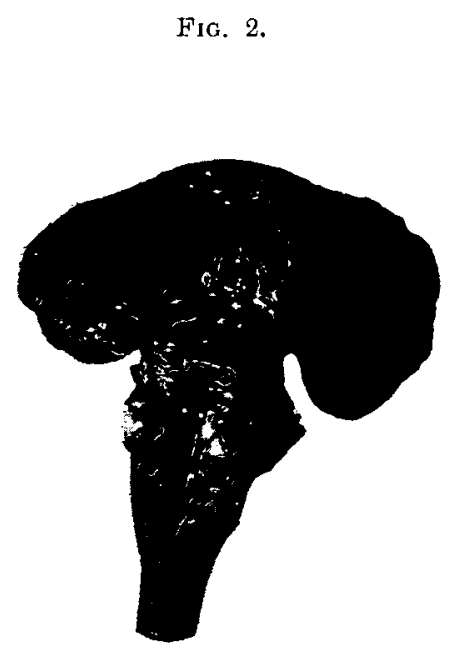

Firi. 3.

FIG. 4.

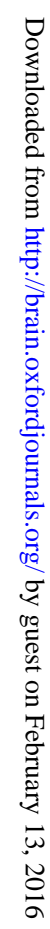
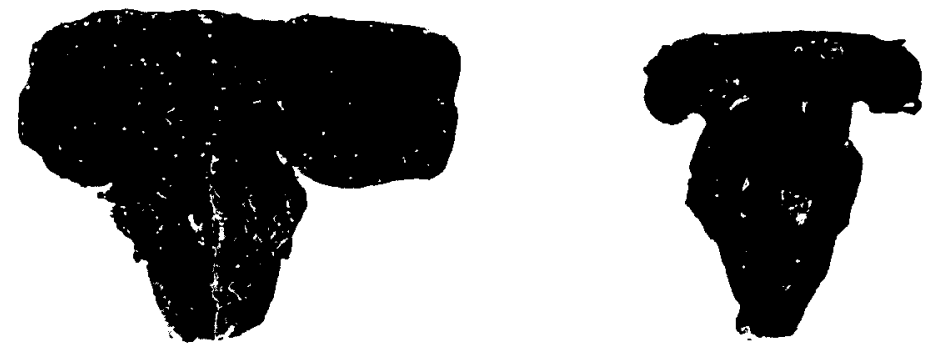

H'IG. 5.

Fici. 6. 


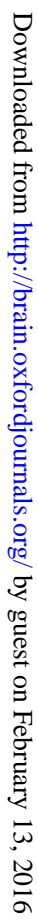

